\title{
Qualidade de vida de estudantes \\ de enfermagem: a construção \\ de um processo e intervenções*
}

\section{NURSING STUDENTS' LIFE QUALITY: BUILDING A PROCESS AND INTERVENTIONS}

\author{
CALIDAD DE VIDA DE ESTUDIANTES DE ENFERMERÍA: \\ LA CONSTRUCCIÓN DE UN PROCESO E INTERVENCIONES
}

\author{
Raquel Aparecida de Oliveira', Maria Helena Trench Ciampone ${ }^{2}$
}

\begin{abstract}
RESUMO
Trata-se de uma pesquisa-ação que teve como objetivos: conhecer as percepções dos alunos de graduação em enfermagem, quanto a sua qualidade de vida, compreender e analisar as demandas por eles evidenciadas no resgate das situações vividas e operacionalizar por meio do grupo operativo direcionamentos e estratégias que possam melhorar a sua qualidade de vida. O estudo foi na PUC/SP. Os dados foram obtidos por meio de entrevistas individuais na primeira fase e nortearam os temas disparadores dos cinco encontros de grupo focal na segunda fase. Os dados dos encontros foram analisados, segundo a análise temática e adaptados do Modelo Ecológico de QVE. Os resultados evidenciaram que a Universidade é um espaço que propicia vivências promotoras e não promotoras de qualidade de vida dos alunos e a necessidade de encontros sistematizados, nos quais alunos e professores discutam a construção individual e coletiva de estratégias de enfrentamento.
\end{abstract}

\section{DESCRITORES}

Estudantes de enfermagem.

Qualidade de vida.

Educação em enfermagem.

\begin{abstract}
This is a research-action studies whose objectives were to know Nursing undergraduate students' perceptions concerning their quality of life; to understand and analyze the demands they highlight when rescuing situations they have experienced; and to make operational, by means of the operative group, directions and strategies that can improve their quality of life. The study was carried out at São Paulo's Catholic University. The data were obtained, in a first stage, through individual interviews. The analysis of the topics from this first stage guided the themes of the five meetings of the focus group in the second stage. The data from the work group were analyzed according to the thematic analysis mode and adapted from the Ecological Model of Quality of Life of Students. The results showed that the University is a place that provides experiences that may promote or not students' quality of life. They also showed the need for systematic meetings in which both students and teachers can discuss the individual and collective development of strategies for facing the problems related to life quality.
\end{abstract}

\section{KEY WORDS}

Students, nursing.

Quality of life.

Education, nursing.

\section{RESUMEN}

Se trata de una investigación que tuvo como objetivos: conocer las percepciones de los alumnos del pregrado en enfermería, en cuanto a su calidad de vida; comprender y analizar las demandas que ellos evidencian en el rescate de las situaciones vividas y actuar por medio del grupo operativo directivas y estrategias que puedan mejorar su calidad de vida. El estudio se llevó a cabo en la PUC/SP. Los datos fueron obtenidos por medio de entrevistas individuales en la primera fase y orientaron los temas lanzados de los cinco encuentros del grupo focal en la segunda fase. Los datos de los encuentros fueron analizados, según el análisis temático y adaptados del Modelo Ecológico de QVE. Los resultados evidenciaron que la Universidad es un espacio que propicia vivencias promotoras y no promotoras de calidad de vida de los alumnos y la necesidad de encuentros sistematizados, en los cuales alumnos y profesores discutan la construcción individual y colectiva de estrategias de enfrentamiento.

\footnotetext{
* Extraído da tese "A Universidade como espaço de vivências de promoção da qualidade de vida dos alunos de enfermagem", Programa Interunidades dos campi da Escola de Enfermagem de São Paulo e Escola de Enfermagem de Ribeirão Preto, Universidade de São Paulo, 2005. ${ }^{1}$ Enfermeira. Professora Doutora do Departamento de Enfermagem do Centro de Ciências Médicas e Biológicas, Pontifícia Universidade Católica de São Paulo (PUC-SP). São Paulo, SP, Brasil. raoliveira@pucsp.br2 Enfermeira. Doutora em Psicologia Social. Professora Titular do Departamento de Orientação Profissional, Escola de Enfermagem, Universidade de São Paulo. Chefe do Departamento de Orientação Profissional da Escola de Enfermagem, Universidade de São Paulo (EEUSP). Pesquisadora do CNPq - Nível 2. São Paulo, SP, Brasil. mhciamp@usp.br
} 


\section{INTRODUÇÃO}

A revisão da literatura a respeito de estudos sobre qualidade de vida (QV) mostra claramente que os autores partem de diferentes enfoques, seja do ponto de vista objetivo (avaliação do grau de satisfação das necessidades básicas e das necessidades criadas em função do nível de desenvolvimento econômico e social de determinada sociedade) ou subjetivo (avaliação do estado de bem-estar, felicidade, amor, prazer, realização pessoal), enfocando ora os âmbitos individuais ora o coletivo.

Em revisão da literatura relacionada à qualidade de vida dos estudantes universitários, evidenciou que o tema vem sendo pesquisado desde a década de $80^{(1)}$.

Essas publicações sugerem que a Qualidade de Vida dos Estudantes (QVE) possa ser entendida como a percepção de satisfação e felicidade, por parte do estudante em relação a múltiplos domínios de vida à luz de fatores psicossociais e contextuais relevantes e estruturas de significados pessoais $^{(1)}$.

Os domínios de vida que são apreendidos pelos autores nestas publicações, para se chegar a um indicador de qualidade de vida entre os estudantes universitários, são: 1) social; 2) individual; 3) acadêmico 4) gênero; 5) finanças; 6) moradia; 7) serviços da universidade; 8) administração universitária e 9) outros (entre estes, saúde)(1).

Estudos da qualidade de vida de estudantes universitários de diferentes áreas citam as estruturas de significados pessoais que incluíram: padrões de interação familiar prevalentes, expectativas e objetivos do estudante e identidade do estudante, especialmente no que diz respeito à autoestima e auto-percepção de competência. Essa formulação complexa do conceito de QVE só será inteligível ao ser colocada em prática nos cenários de múltiplas investigações ${ }^{(1)}$.

Em estudo de revisão bibliográfica, realizado pelas autoras desta pesquisa, com o objetivo de avaliar as publicações sobre qualidade de vida dos estudantes de enfermagem, pudemos encontrar na BDENF (Base de Dados em Enfermagem), específica da área e no MEDLINE (Medical Literature Analysis na Retrietal Systen on-line), base de dados da literatura internacional na área médica e biomédica, 21 publicações datadas dos últimos 7 anos. Estes estudos sobre ensino-aprendizagem em Enfermagem foram selecionados, pois, embora não se relacionem especificamente ao descritor QVE, envolvem circunstâncias objetivas, pontuadas por Benjamim, que incluíram: além de outros indicadores, os da saúde física no momento presente; circunstâncias institucionais tais como ano acadêmico, currículo, número de cursos, e os fatores psicossociais, como estresse e estados emocionais prevalecentes nos estudantes de enfermagem (depressão e ansiedade). Esta revisão da literatura permitiu-nos constatar a carência de estudos mais específicos a respeito de qualidade de vida de estudantes de enfermagem.
Esta situação nos levou ao desenvolvimento da presente investigação, partindo do reconhecimento de situações presentes na formação profissional do enfermeiro que determinam e podem gerar tanto processos potencializadores de qualidade de vida, como processos destrutivos da mesma, comprometendo a saúde física e mental do futuro profissional.

\section{Objetivo geral}

Identificar as percepções que os alunos de graduação em enfermagem têm em relação à qualidade de vida, tendo em vista as experiências vivenciadas no processo de formação.

\section{Objetivos específicos}

Identificar a compreensão que esses alunos têm sobre a própria qualidade de vida e analisar as principais demandas por eles evidenciadas no resgate das situações vividas.

Operacionalizar, por meio do grupo operativo, trocas relacionais que favorecem os direcionamentos e estratégias utilizadas que possam gerar melhoria da sua qualidade de vida.

\section{MÉTODO}

As bases metodológicas que fundamentaram este estudo foram as da pesquisa qualitativa, na modalidade da pesquisa-ação. Isso se justifica, pois consideramos que essa modalidade de pesquisa favorece o acesso à intersubjetividade presente no propósito de revelar a compreensão que os alunos têm em relação ao seu vivido, durante a formação, quanto a sua qualidade de vida e a futura qualidade de vida no trabalho.

Para a obtenção dos dados e intervenção, a técnica escolhida foi a de grupo focal, associada a alguns elementos da técnica de grupo operativo ${ }^{(2)}$.

A Técnica de Grupo Focal pode enriquecer e ampliar a perspectiva de compreensão em uma pesquisa, assim como possibilitar intervenções transformadoras que contribuam para interações mais humanas e efetivas ${ }^{(3)}$.

Esta estratégia metodológica possibilita reunir diferentes atores em formação, num mesmo espaço de investigação, promovendo a reflexão crítica sobre o cotidiano de ensino - aprendizagem. Enquanto estratégia metodológica permite, ainda, aos pesquisadores, observar pontos consensuais e as divergências, além das diferentes maneiras de superação dos problemas evidenciados em diferentes campos que compõem os cenários $^{(3)}$.

Os grupos focais são reuniões com um pequeno número de informantes (de seis a quinze), que devem contar com um coordenador (moderador) para intervir, no sentido de focalizar e aprofundar a discussão. Os participan- 
tes precisam ser escolhidos a partir de um grupo de referência, cujas vivências sejam pertinentes ao objeto de estudo na pesquisa, isto é, neste tipo de pesquisa a amostra é sempre intencional ${ }^{(4)}$.

O coordenador deve garantir um ambiente que possibilite a expressão de todas as opiniões dos participantes sem que isso leve a um clima de disputa. O coordenador deve ser alguém que atue como facilitador do processo mantenha a discussão sobre o tema central, fazendo sumarizações da discussão, sempre que necessário, auxiliando o grupo a fazer uma reflexão conjunta, ou a trazer novas questões para aprofundamento.

A operacionalização da observação mais apurada deve ser feita de modo conjunto pelo coordenador e no mínimo por um observador. Este observador deve assumir a tarefa de registrar todos os acontecimentos no grupo, incluindo os aspectos não verbais presentes na comunicação dos participantes, desde o início até o final da reunião.

\section{Campo do estudo}

A pesquisa foi realizada com alunos do Curso de Enfermagem do Departamento de Enfermagem do Centro de Ciências Médicas e Biológicas, Campus Sorocaba, da Pontifícia Universidade de São Paulo. Para tanto houve previamente ao início da pesquisa, a autorização da instituição.

\section{Sujeitos/Atores da Pesquisa}

Constituiu-se de 11 alunos que estavam freqüentando o curso de graduação em enfermagem matriculado nas segunda, terceira e quarta séries, pois, considerou-se que nessas séries estes vivenciaram pelo menos um estágio na área profissional de aprendizado. Assim excluiu-se o convite aos alunos da 1ạ série.

A autorização para realizar os grupos com as alunas foi precedida pelo encaminhamento e aprovação do projeto de pesquisa pelo Comitê de Ética, de acordo com a Resolução $196^{(5)}$.

Os cinco encontros de grupo focal aconteceram no período de agosto a setembro de 2005 , em local previamente acordado pelos alunos participantes e pesquisadoras. Como coordenadora dos grupos, utilizei como temas disparadores, material que emergiram de entrevistas indi-viduais realizadas com alunos formados de 2003. Nessas entrevistas objetivou-se captar o significado que esses alunos atribuíam ao termo qualidade de vida e os relatos de experiências por eles vividas e consideradas situações promotoras e não promotoras de qualidade de vida durante o curso. Para esses dados se utilizou à análise temática e constituíram-se em objeto de outro estudo(6).
Ao término de cada sessão eu como coordenadora e a observadora no reuníamos para analisar o conteúdo apreendido tendo apoio nas anotações realizadas no encontro. No momento dessa primeira análise, a atenção estava voltada ao que os porta-vozes ${ }^{(a)}$ do grupo tinham tentado comunicar. No encontro seguinte, eram apontados ao grupo os vários aspectos explicitados pelos porta-vozes, assinalando-se que estes pertenciam também ao grupo, ou seja, emergiam em decorrência da interação dos membros do grupo entre si e com a coordenação.

\section{ANÁLISE E DISCUSSÃO DOS RESULTADOS}

O conteúdo dos grupos foi apresentado na forma de crônicas e para análise dos resultados, elaboramos uma adaptação do Modelo Ecológico proposto por Benjamin para os estudantes de enfermagem ${ }^{(7)}$ (Figura 1). Este modelo reconhece a QVE como sendo de caráter multidi-mensional e, como conseqüência da interação dinâmica do tipo do estudante, dos eventos situacionais, dos estágios de transição por eles vividos e do ajuste pessoa-ambiente através dos domínios de vida relacionados às experiências nos diferentes contextos. Para os estudantes de enfermagem, incluímos no domínio acadêmico o espaço de campos de prática, onde consideramos as relações com os profissionais da equipe de saúde.

A análise dos encontros indica claramente que os colaboradores ao formularem e discutirem o significado de QV relaciona-na com os diferentes conceitos estabelecidos pelos autores presentes na literatura. Esses conceitos, ora apontam para uma interface entre a qualidade de vida no trabalho, ora para a qualidade de vida enquanto estudante. $\mathrm{Na}$ discussão dos conceitos, os sujeitos participantes destacaram que o tema está intimamente ligado não somente à vida profissional, como também, à vida pessoal, e que o mesmo faz parte do cotidiano de cada um.

Qualidade de vida é um tema que abrange muita coisa. Como pessoa e se dar bem como profissional, claro que você não pode... não dá para separar, você tem que ter um equilíbrio, responsabilidade, ter seu compromisso com amor, tanto com a Instituição quanto com a sua família (Henrique).

(a) Porta-voz é o depositário da ansiedade grupal, conjuga a verticalidade e a horizontalidade, isto é, fala de sua vida pessoal articulando-a com o processo atual que acontece no aqui e agora de grupo em relação a tarefa ${ }^{(2)}$ 


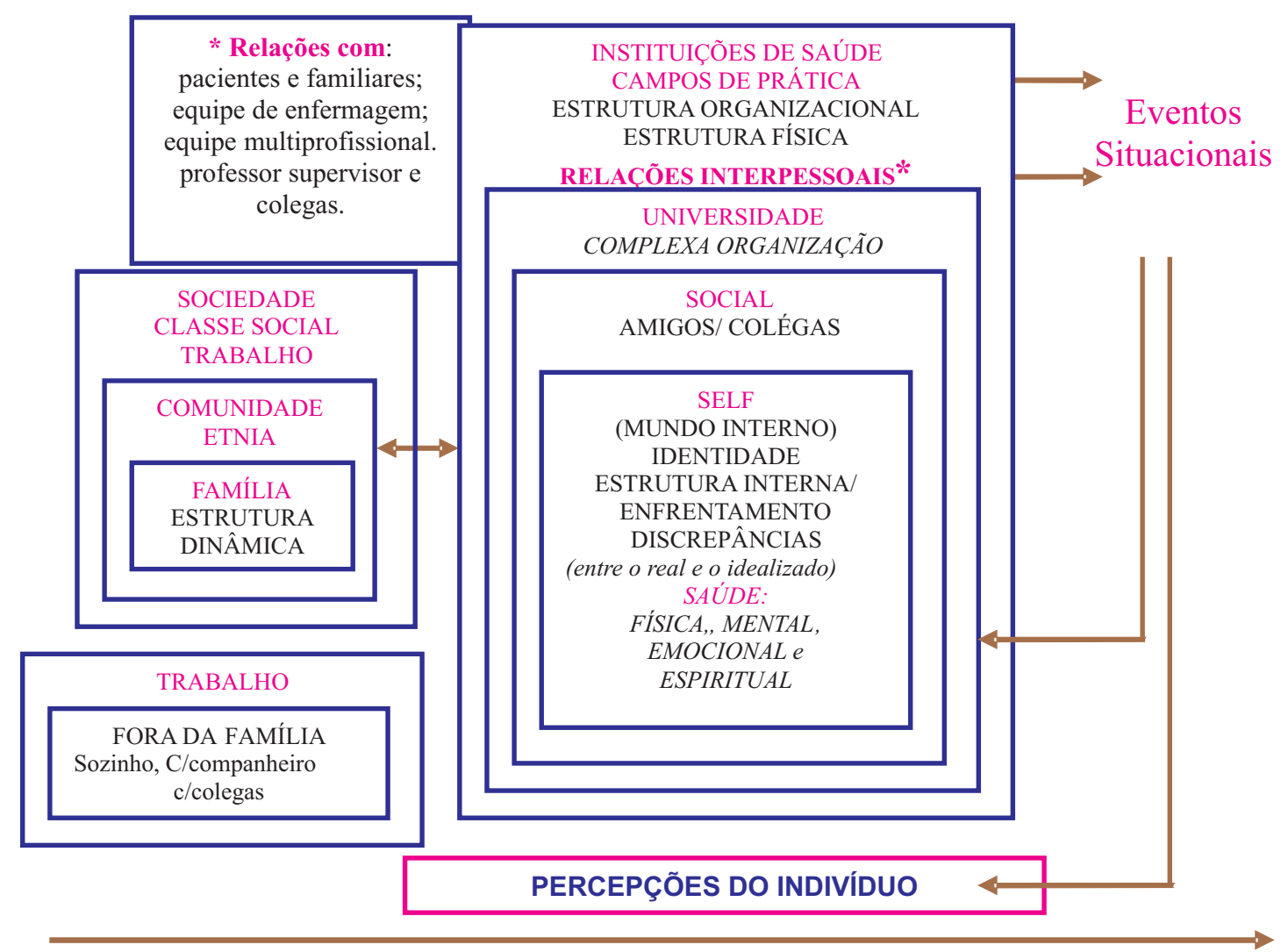

Figura 1 - Modelo Ecológico de QVEEnf - Adaptado do proposto por Benjamin $(1994)^{(7)}$.

No primeiro encontro, identificamos alguns domínios citados pelos autores que tratam de QVT. É possível identificar que os alunos participantes fazem identificações projetivas quanto ao futuro profissional, enquanto enfermeiros, considerando a questão da carga horária excessiva de trabalho; a baixa remuneração e o mercado de trabalho que exige produtividade. Outro ponto ressaltado foi à insegurança gerada pelo não reconhecimento e valorização das atividades executadas pelos alunos durante a formação. Isso é por eles percebido, tanto por parte do docente, dos enfermeiros de campo, como de outros profissionais. A falta de acolhimento dos enfermeiros em relação às dificuldades vividas no início da profissão; os conflitos gerados a partir do enfrentamento de situações profissionais em diferentes contextos vividos na formação, a preocupação em dar continuidade a uma assistência de qualidade para os clientes, aliados ao desejo de serem profissionais diferentes dos modelos que encontram no campo prático, constitui-se em dilemas para o aluno de enfermagem, que interferem desfavoravelmente em sua qualidade de vida.

Henrique expressa ... carga horária excessiva, não está aí à remuneração (olha para o esquema apresentado), mas vai pesar muito. As empresas estão cada vez mais visando o enfermeiro como produto mesmo, produtivida- de, cada vez mais como mão de obra barata,... aí se torna difícil, é um conflito mesmo... acaba se decepcionando com todo este clima.

Ana desabafa: ... o estágio é uma coisa importante, será que quando eu me formar vou conseguir trabalhar em equipe, dar uma assistência adequada, conseguir fazer uma prescrição a ser cumprida, a ser feita... a gente estudou tanto para fazer isso, será que eu como chefe vou conseguir, será que os meus auxiliares vão ser capazes?... E fico saindo irritada do estágio, ninguém leu. Aqui a aluna se refere às anotações de enfermagem.

Nos depoimentos dos alunos participantes dos grupos, ressaltam-se as questões que denotam a vivência de práticas que pouco privilegiam ações direcionadas ao desenvolvimento da elaboração, da autonomia e criatividade. Apreende-se que ocorre uma adaptação passiva dos mesmos à realidade, expressa por um processo de disciplinarização no decorrer do curso.

Nessa mesma direção, há muitas situações que favorecem a disciplinarização das futuras enfermeiras, estimulando a negação de si como ser humano, fazendo que estas se tornem, por vezes, um mero objeto, pois não são valorizadas as suas histórias, o seu saber prévio, assim como seus sentimentos, idéias, anseios e necessidades ${ }^{(8)}$. 
No segundo encontro, a narrativa dos colaboradores mostra quais são as situações promotoras de qualidade de vida. Apontam que o contexto da vida acadêmica propicia mudanças, conquista da sua identidade e certa liberdade, em relação à vida pessoal, quando vivem as experiências inerentes ao morar fora de casa, quando são provenientes de outras cidades.

Paola diz: Para mim, só o fato de entrar na faculdade, mudou muito a minha qualidade de vida. Mudou o meu relacionamento aluno/professor, conhecer vários amigos, as atividades acadêmicas, morar sozinha, ter mais dever e mais consciência. Eu mudei bastante o meu jeito de pensar.

Assinalam que as disciplinas de Ética, Psiquiatria e Antropologia, possibilitam a reflexão e a crítica e a pensarem na sua qualidade de vida. Por serem estas disciplinas da área de Ciências Humanas, estas foram lembradas como espaços importantes para suporte dos aspectos relacionais, percebidos como promotores de QV.

O atendimento oferecido pelos funcionários da escola: da secretaria, da biblioteca e de outros setores, é citado pelos colaboradores, como sendo de muita importância, no sentido de acolhimento e de saber que podem contar com um ombro amigo.

A gente não pode esquecer dos funcionários, da biblioteca, da secretaria, eles se preocupam com tudo que acontece com a gente; no Setal(b) , tem pessoas muito legais, preocupam-se com os alunos como seres humanos. Elas dão muito apoio para gente (Rosa).

O cuidado prestado aos clientes, quando contribui para a sua melhora de condições de saúde, é referido como fonte de satisfação e bem estar para o aluno. Corroborando com o explicitado pelos alunos, na prática docente acompanhando os alunos nas atividades práticas, presenciamos muitas situações em que os mesmos demonstram alegria e satisfação quando podem perceber resultados imediatos de melhora do cliente, a partir da sua assistência.

Flor afirma: ... quanto ao cuidado prestado, você faz a coisa certa, você prescreve aqueles cuidados que vão contribuir para a melhora do paciente, a gente fica com aquela sensação de missão cumprida. Será que vai ser assim todo dia quando eu trabalhar? Tem que fazer a diferença todo dia, fazer o melhor, fazer o melhor para ele e consequentemente para mim; com certeza a gente se sente bem com o nosso serviço....

Este servir implica uma negação e esquecimento de si, dos seus desejos, vontades e aspirações que parecem não se concretizar senão na realização e na satisfação do outro $^{(8)}$.

O processo grupal mostrou que é preciso possibilitar ao aluno expandir esta satisfação de cuidar do outro para

(b) Setal - Secretaria do alunado o cuidado de si e para o cuidado entre si, isto é, entre os colegas e professores. Para tanto, o docente que ensina, também deve estar preocupado em cuidar do aluno e do grupo em suas relações de ensino, pois o professor também é percebido como modelo para o aluno ou, um antimodelo.

Os depoimentos no grupo enfatizam o quanto o relacionamento acolhedor da professora de administração facilitou o seu processo de amadurecimento.

Paola conta que: ... foi a partir deste ano,... fez-me acordar mais, me empenhar, eu gostava do curso, mas era muito imatura, foi por causa da professora de Administração... foi a partir daí que eu dei o meu mergulho.

Esse depoimento está em consonância com a pesquisa sobre humanização da assistência, que enfatiza a necessidade de humanizar o ensino e descreve as estratégias facilitadoras no ambiente de aprendizagem adotadas pelo professor, como: atuar como mediador do conhecimento, favorecer a autonomia do aluno, estar próximo do aluno, perceber o potencial do aluno(9). Neste sentido, as intervenções de acolhimento por parte do docente propiciam que o aluno melhore a sua auto-estima e passe a protagonizar a sua história, a partir de referências positivas.

As atividades acadêmicas extra-curriculares, como participação em Pesquisas de Iniciação Científica, Ligas e no Projeto Nefroriso, é apontada em consenso, pelos alunos participantes, como espaços promotores de qualidade de vida. Os alunos encontram, nesses espaços, oportunidades para exercitarem uma aprendizagem ativa, dialogada, desenvolverem a criatividade, a capacidade de trabalhar em grupos e terem o seu trabalho reconhecido.

Rosa lembra da participação dos alunos no Projeto Nefroriso $^{(c)}$ :

A gente não pode esquecer do Nefroriso que é uma coisa que ajuda muito a gente. $\mathrm{O}$ ano passado me fez muito bem, eu entrei na última semana e foi maravilhoso. Tinha que ter uma vez por mês algo parecido com isto!

A organização dos alunos em relação à participação do Centro Acadêmico é percebida como tendo falta de articulação entre os mesmos. A mesma característica, de falta de articulação, também foi destacada pelos alunos em relação aos enfermeiros em suas práticas profissionais. Estes são percebidos como pouco participativos de atividades de articulação política, direcionada para reivindicações de melhoria para a sua categoria, enquanto classe trabalhadora.

Esse comportamento pode ser explicado pela construção histórica da profissão que se desenvolveu em um contexto de pratica religiosa, caritativo, marcado por nor-

(c) Atividade extra-curricular organizada e desenvolvida pelos alunos. Tem como objetivo propiciar momentos de descontração e alegria à pacientes e funcionários da Unidade de Hemodiálise. 
mas e limites rígidos, sem reconhecimento da prática como trabalho profissional, mas sim, como uma atividade que seria recompensada, em uma outra dimensão da vida pósmorte.

Neste sentido, os resultados dos encontros grupais apontam este servir uma negação e esquecimento de si, dos seus desejos, vontades e aspirações que parecem não se concretizar senão na realização e na satisfação do outro(8).

Esta representação, embora tenha perdido sua força, ainda se reflete no contexto de trabalho atual da enfermagem. Isto pode ser percebido em relação às horas de trabalho, que ultrapassam a jornada legal, ao rigor no cumprimento de disciplina, à baixa remuneração recebida, com pouco reconhecimento social pelo trabalho prestado e as condições de trabalho, muitas vezes insalubres.

Estas são evidências que mostram a importância de se ter Políticas de Recursos Humanos que adotem a preocupação com a qualidade de vida dos trabalhadores de enfermagem, identificando e intervindo sobre as situações potencializadoras de um perfil desfavorável de saúde e de vida desses profissionais.

No 3 o Encontro, os colaboradores comentam situações não promotoras de QV que se relacionam a domínios referentes às instituições de ensino (campus e demais locais de estágios). No que se refere ao campus, foi assinalada para os alunos de enfermagem a falta de atividades e de espaços de acolhimento e de lazer. Neste aspecto, relatam, ainda, o quanto os alunos do curso de medicina são privilegiados em relação aos de enfermagem, no que se refere aos espaços de lazer que estes tem e que não são compartilhados, no campus, com os demais.

Quanto aos locais de estágios, trazem as questões das relações conflituosas com as enfermeiras já formadas e com as outras categorias profissionais.

Gisele comenta: Aconteceu com a gente, a enfermeira falou que a gente só atrapalha só que a gente faz tudo lá, disse que a gente só ri , conversa e não faz nada.

A narrativa dos alunos mostra que a dimensão das relações interpessoais no trabalho e na vida de estudante são geradoras de insatisfação, quando reconhecem as dificuldades de relacionamento entre os alunos de diferentes cursos e dentre os do próprio curso de enfermagem. Revelam questões de desunião e competitividade entre os alunos.

Henrique comenta: ... é criar... interação entre cursos, mas a faculdade não tem nada que cria esta interação com os cursos..., não tem nada, vamos dizer se você tivesse um momento para discutir alguma coisa.

Quando abordam a relação professor-aluno, no processo de formação consideram que prevalecem as situações geradoras de medo, insegurança e pressão.
Paola: ... o professor cobra muito do aluno e quando você faz uma pergunta, ele vira com uma coisa que vai te machucar e não dá nem para você responder, ele trata mal o aluno, na frente de todo mundo....

As características dificultadoras da aprendizagem, referidas por alunos de graduação em Enfermagem são: a aprendizagem da teoria diferente da prática; o medo do professor; o professor que adia a resposta às perguntas; o professor que não responde às perguntas dos alunos; 0 professor frustrado; a não familiaridade do professor com a especialidade; a insegurança do professor quanto ao desenvolvimento do aluno e quanto ao conhecimento; o professor que não tem vivência com o aluno e as dificuldades dos alunos que não trabalham na área ${ }^{(9)}$.

Essas características mostram consonância com os relatos dos colaboradores da presente pesquisa, que abordam a dicotomia da teoria e da prática; a falta de acolhimento por parte do professor supervisor; o professor que expõe o aluno; o professor que vai ensinar e não sabe os passos importantes e o professor que não está preparado para lidar com o aluno crítico.

A convivência com os enfermeiros de campo é percebida pelos colaboradores da presente investigação, como um indicador de conviver com o não exemplo e pela falta de acolhimento. Esse foi um tema recorrente nos encontros. Estas situações vivenciadas por eles em campo prático, geram sentimentos de impotência para si, tanto no sentido pessoal quanto no sentido profissional, implicando em uma baixa auto-estima, bem como, uma desvalorização profissional.

Um estudo ${ }^{(10)}$ conclui que as médias do IQV nos diferentes anos do curso mostraram queda no decorrer do $2^{\circ}$ ano, quando os estudantes são inseridos no campo prático.

O período de formação constitui-se em um tempo, onde os alunos vivem a experiência de se conhecer como parte do ir se preparando para ser profissional. Muitas vezes, a sensibilidade estando excluída das relações interpessoais, acarreta perda de um canal importante para acessar a leitura da realidade, para a compreensão empática do outro.

No quarto encontro, os colaboradores identificam experiências acadêmicas que foram promotoras de qualidade de vida, como: participação em atividades extracurriculares em ambulatórios e estágios, iniciação científica, monitorias, receber o reconhecimento do outro, o elogio da professora, a superação dos seus limites e o resultado da prática superando o medo. Como ferramenta para acessar a qualidade de vida, destacaram a persistência, o apoio familiar, o desempenho profissional, a força interior, o outro, a fé e a espiritualidade.

Ana conta que: Eu acho que foi a minha monitoria em parasitologia, me ajudou muito e recebi muitos elogios do professor... não sabia que era tão importante aqui... cada dia que passa sinto-me mais importante ali. 
Quando estimulados a pensarem em estratégias que poderiam contribuir para melhoria da QV, enquanto estudantes de enfermagem, em processo de formação, os co- laboradores destacam os aspectos, que coincidem com os pontuados no modelo ecológico adaptado para os estudantes de enfermagem (Figura 2)

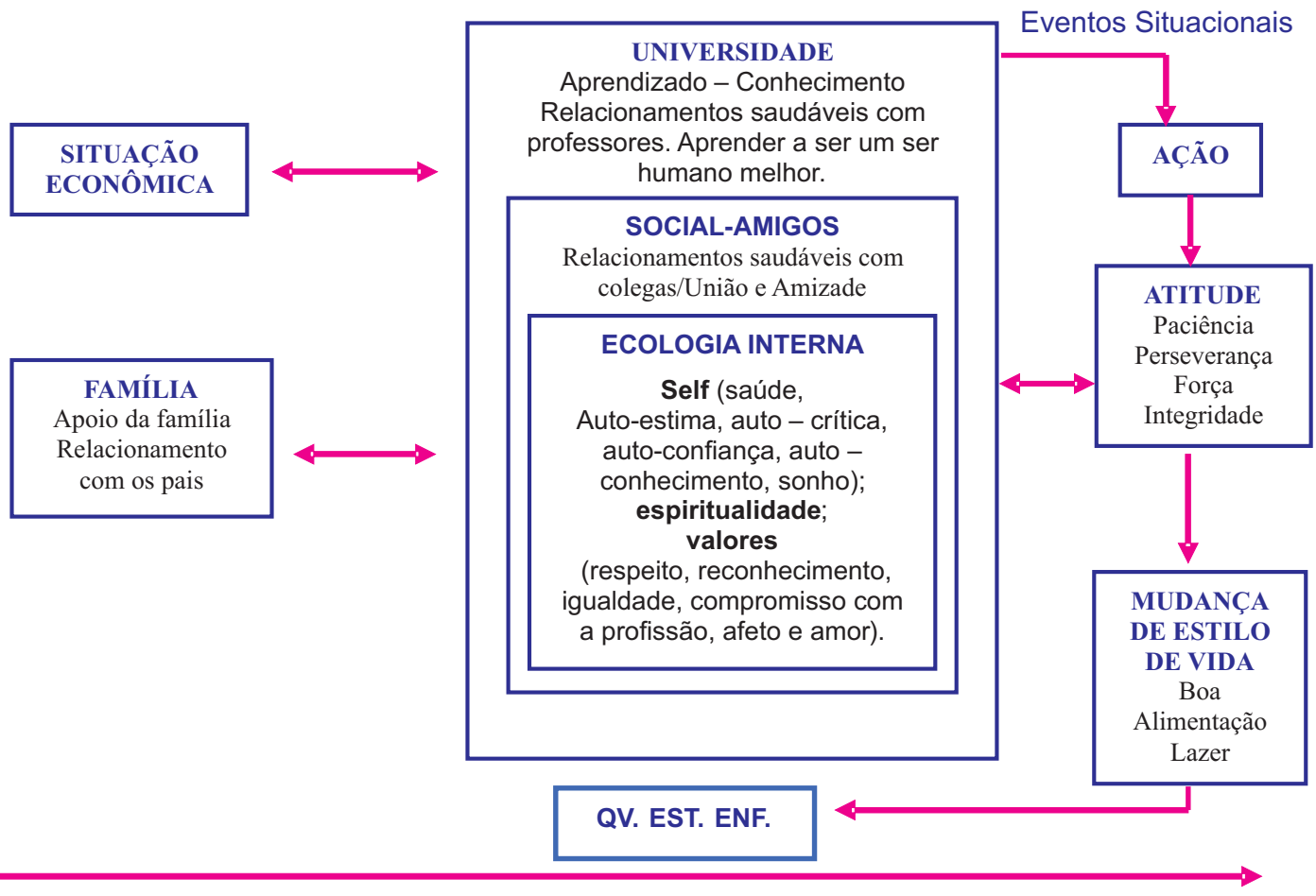

Figura 2 - Estratégias para melhoria da QVEst de Enf., segundo o Modelo Ecológico de QVEst. Enfermagem. Adaptado do proposto por Benjamin ${ }^{(1)}$

Ao analisarmos e compararmos as estratégias indicadas pelos alunos que poderiam contribuir para a melhoria da qualidade de vida, enquanto estudantes de enfermagem, durante a formação, com as dimensões do Modelo Ecológico ${ }^{(1)}$, adaptadas para os estudantes de enfermagem, observamos que algumas das dimensões como as Instituições de Saúde (Campos de Prática); a vida social do Campus, não foram exploradas em profundidade e outras como as referentes à Universidade em sua organização e estrutura curricular (aspectos acadêmicos), não foram sequer citadas.

As dimensões citadas com maior profundidade dizem respeito às dimensões da Ecologia Interna. Isto demonstra uma necessidade de aprendizado para reconhecimento do seu mundo interno e da sua relação com o mundo externo e a elaboração de estratégias, sejam elas individuais e/ou coletivas de enfrentamento, para melhoria da QV enquanto estudantes.

Flor: Eu dou muito valor à espiritualidade,... ao autodomínio... bondade, brandura... cultivar cada dia... .

Em relação à dimensão da espiritualidade, a religiosidade representa um contato com o divino, é a maneira como a pessoa se conecta com o que acredita serem forças protetoras ou negativas em seu cotidiano ${ }^{(11)}$. Essa afirmação confirma a referência dos colaboradores desta pesquisa, pois buscam, na espiritualidade, subsídios para tentar sustentar as situações percebidas como não promotoras de qualidade de vida.

Ao discutirmos a dimensão relacionada aos valores, foram citados pelos colaboradores, nesta pesquisa: respeito, reconhecimento, igualdade, compromisso com a profissão, afeto e amor.

Os colaboradores apontam, com muita ênfase, que a qualidade de vida no trabalho durante a formação, assenta-se sobre a discriminação dos papéis desenvolvidos, principalmente entre alunos e professores.

Neste sentido, afirmamos que é necessária uma maior aproximação do professor ao universo do vivido do aluno. Como professores de enfermagem, adotamos um discurso rico de integração, de humanização, de competências para o conhecer, fazer e ser, mas não nos permitimos dialogar sobre esse processo durante as vivências do aluno e tendemos a deixar de lado a dimensão do sentir. Os colaboradores deixam explicito o quanto não lhes é permitido o sentir, pois percebem que, para ser enfermeiro, vive-se ainda a contradição entre o sentir, o pensar e o agir. Entendemos que estes relatos apresentados sinalizam para que se explore esta contradição. É necessário tomar consciência dela e então, estabelecer estratégias de superação. Neste aspecto o professor pode ser a ponte para facilitar o aprendizado para a vida. 
O 5 o Encontro representou o último momento da coleta de dados, foi utilizado para a devolutiva e avaliação dos alunos sobre o processo grupal.

Os colaboradores quando avaliam a sua própria QV, referem que esta não está boa e pontuam a falta de autoconhecimento, baixa auto-estima, as mudanças de rotina de vida e de escolhas que terão que fazer.

Os alunos demonstram de forma recorrente, o quanto Ihes falta o acolhimento quanto às questões internas (os sentimentos sobre o vivido).

Quanto à construção da $\mathrm{QV}$, reconhecem a participação de cada um, como importante, seja individualmente ou em grupo. Percebem a QV com uma característica muito pessoal que, apesar de todos estarem empenhados, cada um terá que buscar a sua.

Entendem que a mudança só ocorre quando há o conflito e concluem, atribuindo à Instituição/Escola e aos professores a falta de estímulo, apoio para as mudanças, para as iniciativas dos alunos, frustrando, por vezes, a continuidade dos seus projetos.

A este respeito, consideramos pertinente que os professores passem a valorizar e a incentivar iniciativas e participações dos alunos em projetos extra-classe.

A participação do grupo foi identificada pelos alunos como um espaço de acolhimento, troca de experiências e destacaram momentos em que o grupo foi terapêutico. Esses momentos são esperados em um grupo operativo, apoiados na teoria pichoniana(d) de que neste tipo de trabalho há aberturas para reelaboração sobre o vivido.

Brenda: ... é uma terapia em grupo e é muito bom...; Lua: foi muito terapêutico para todo mundo...; Rosa: O que foi muito positivo é ser cada um de um ano...; cada turma carrega uma história, uma vivência e é legal poder trocar essas idéias...; Henrique: ... a gente não teve aquela pressão... a gente ficou bem à vontade...; Lua a gente tem muito medo de ser julgado, avaliado... Aqui não, foi gostoso... .

Os colaboradores falaram da mútua representação interna positiva que ocorreu no grupo, isto é, do quanto aprenderam com o partilhar experiências e vivências com o outro. As falas convergiram para sentimentos de gratificação.

Partindo da vivência grupal, os alunos também indicam a necessidade de continuidade do grupo em outros espaços do ambiente Universitário, como favorável à melhoria da qualidade de vida enquanto estudantes.

\section{CONSIDERAÇÕES FINAIS}

Este estudo permitiu identificar que existem momentos promotores de qualidade de vida dos alunos de enfer-

(d) Trata-se da Teoria de Grupos Operativos descrita por Pichon-Rivière magem durante a sua formação na Universidade. Mostrou que este é um espaço onde existem os dois pólos, ou seja: situações favoráveis e desfavoráveis em relação à promoção da qualidade de vida.

A metodologia utilizada favoreceu discussões e intervenções potencializadoras de qualidade de vida aos estudantes. Esse fato nos leva a considerar que tanto a qualidade de vida do estudante de enfermagem como as intervenções puderam ser construídas no processo grupal. Este fato nos leva a considerar que a formalização de um espaço promotor de qualidade de vida é possível e necessário.

No que se refere às estratégias para a melhoria da QV enquanto estudantes observamos que estas são apresentadas no grupo pela somatória de estratégias individuais, provavelmente pela falta de um "modelo" de estratégias coletivas que seja internalizado pelos alunos em função de suas experiências com o grupo de professores, colegas e outros profissionais, com os quais convivem.

Os resultados desse estudo, nos permitem falar em defesa da necessidade de preparo dos futuros profissionais de saúde e dos docentes para o desenvolvimento do cuidado de si, como precedente da condição para o cuidar de outros.

Isso porque, o aluno em formação vivencia no seu processo de aprendizagem, tantos os aspectos promotores como os não promotores de qualidade de vida. Posteriormente, se não há elaboração, tendem a reproduzir o mesmo modelo em suas práticas profissionais.

O momento presente traz à tona o grande desafio de lidar com a reforma curricular que possibilite flexibilidade de estratégias e espaços para que o estudante descubra quem é, se compreenda, promova seu crescimento e aperfeiçoamento como ser humano e futuro profissional.

Neste sentido, recomendamos que algumas estratégias sejam estimuladas e introduzidas nas práticas de ensino-aprendizagem, são elas:

- Aprendizagem compartilhada, ou seja, é a ocasião em que a teoria e prática estão fundamentadas no processo colaborativo de equilíbrio de poder e responsabilidade pelo aprendizado e que favorece a reciprocidade, por intermédio da comunicação e das relações interpessoais. Esta abordagem permite ao aluno transcender a frustração e a dependência do professor, propicia autonomia, um ambiente estimulador em que o aluno se sente responsável e satisfeito.

- Oportunizar vivências que minimizem o stress. Estas práticas, além de proporcionar conforto, permitem, na vivência, o aprendizado de estratégias de enfrentamento.

- Elaboração de um diário de campo, pelo aluno, onde este registre sistematicamente seus sentimentos diante das práticas e espaços grupais, no final dos períodos de 
estágio com estratégias de avaliação, que permitam aos alunos sentirem-se valorizadas, pois podem contar com um espaço para verbalizar suas dúvidas e ansiedades, seus questionamentos e temores, permitindo um maior crescimento pessoal e profissional.

- Promover experiências que visem a sensibilização dos alunos quanto às relações a serem construídas com os colegas, professores e equipe de profissionais. Exercitar o respeito, os sentimentos de solidariedade, respeito e amorosidade, expressos por meio de atitudes de apreço, de consideração são fundamentais no processo de formação dos enfermeiros.

- Instituir um espaço de supervisão dos estudantes visando assistência para lidar com seus sentimentos e canalizálos para melhoria das relações que estabelecem.

- Instituir um espaço para os docentes que supra a necessidade destes para auxiliar na expressão de afetos por

\section{REFERÊNCIAS}

1. Benjamin M. The quality of student life: toward a coherent conceptualization. Indicators. 1994;31:205-64.

2. Pichon-Rivière E. O processo grupal. 6a ed. São Paulo: Martins Fontes; 2000.

3. Chiesa AM, Ciampone MHT. Princípios gerais para a abordagem de variáveis qualitativas e o emprego da metodologia de grupos focais. In: Chianca TCM, Antunes MJM, organizadores. Classificação Internacional das Práticas de Enfermagem em Saúde Coletiva - CIPESC. Brasília: ABEn; 1999. p. 306-33.

4. Ciampone MHT, D'Agnoll C. Grupos focais como estratégia metodológica em pesquisas na enfermagem. Rev Gaúcha Enferm. 1999;20(1):5-25.

5. Conselho Nacional de Saúde. Resolução n. 196, de 10 de outubro de 1996. Dispõe sobre diretrizes e normas regulamentadoras de pesquisas envolvendo seres humanos. Mundo Saúde. 1996; 21(1):52-61.

6. Oliveira RA; Ciampone MHT. A Universidade como espaço de vivências promotoras e não promotoras de qualidade de vida de alunos de enfermagem. Texto Contexto Enferm. 2006; 15(2):254-61. parte dos estudantes. A supervisão tem múltiplos propósitos e não está limitada somente aos aspectos técnicos.

Essas recomendações justificam-se pela evidência de que o contato direto com seres humanos em processo de sofrimento coloca aluno e professor diante de seus próprios conflitos e frustrações, sendo assim, é importante que o professor proporcione momentos de aconseIhamento e escuta, de modo que o aluno possa trabalhar situações de transferência e contrareferência e assim possa elaborar as vivências que vão acontecendo no trabalho de aprender a cuidar de si e dos outros.

Ao estudar a QVEENF, ficou evidente a importância do papel do docente, portanto, as intervenções no aprendizado da qualidade de vida dos futuros enfermeiros, passa pelo cuidado também dos docentes, pois não se pode desarticular a reprodução das situações não promotoras de QV presentes na prática do ser docente em diferentes contextos da situação de aprender e de ensinar.

7. Oliveira RA. A Universidade como espaço promotor de qualidade de vida:vivências e expressões dos alunos de enfermagem [tese]. São Paulo: Escola de Enfermagem, Universidade de São Paulo; 2005.

8. Oliveira ICD, Fernandes JF, Lunardi VL. Como a futura enfermeira está se cuidando e vem sendo cuidada no processo de graduação. Texto Contexto Enferm. 2000; 9 (3):133-52.

9. Cavalcante MB. Humanização no processo de formação de profissionais de saúde: experiências de alunos do curso de graduação de enfermagem [tese]. São Paulo: Escola de Enfermagem, Universidade de São Paulo; 2003.

10. Kawakame PMG, Miyadahira AMK. Qualidade de vida de estudantes de graduação em enfermagem. Rev Esc Enfem USP. 2005;39(2):164-72.

11. Hansen TJ. The spiritual dimension of individuals: conceptual development. Nur Diag. 1993;4(4):140-6. 